\title{
Impact of Using m-Health App on Improving Undergraduate Students' Sports and Health Habits and Their Attitudes toward Its Use
}

\author{
Ali Al Musawi, Wajeha Al-Ani, Mohamed Al-Aghbari \\ College of Education, Sultan Qaboos University, Seeb, Oman \\ Email: asmusawi@squ.edu.om,wajeha@squ.edu.om,malaghbari@squ.edu.om
}

How to cite this paper: Al Musawi, A., Al-Ani, W. and Al-Aghbari, M. (2019) Impact of Using m-Health App on Improving Undergraduate Students' Sports and Health Habits and Their Attitudes toward Its Use. E-Health Telecommunication Systems and Networks, 8, 1-9. https://doi.org/10.4236/etsn.2019.81001

Received: January 19, 2019

Accepted: March 23, 2019

Published: March 26, 2019

Copyright $\odot 2019$ by author(s) and Scientific Research Publishing Inc. This work is licensed under the Creative Commons Attribution International License (CC BY 4.0).

http://creativecommons.org/licenses/by/4.0/

\begin{abstract}
This study aims to explore the Sultan Qaboos University undergraduate students' perceptions and attitudes towards using $\mathrm{m}$-Health app and its impact on improving their sports and health habits. Triangulation was used by applying a questionnaire and focus groups interviews to answer the research questions. The survey sample was (20) male and female students from four science and humanities colleges. Both quantitative and qualitative findings unequivocally reveal the students' positive perceptions and attitudes toward the use of the mobile health app. No statistically significant differences were found between the responses of either males or females, or the science and humanitarian colleges of the sample students. In light of these findings, the study set forth its conclusions and recommendations.
\end{abstract}

\section{Keywords}

Mobile Health Apps, Sultan Qaboos University, Students, E-Health

\section{Introduction}

Advantages of mobile phone use in physical activity can be seen by the increasing use of the m-Health apps. Individuals are increasingly using mobile phones to monitor their health and physical fitness. Mobile health apps (m-Health apps) are categorized to: 1) fitness and general health apps and 2) disease management apps [1]. It seems that $\mathrm{m}$-Health apps are important to use in the curriculum of science-based colleges, medicine and nursing in specific [2] [3].

[4] explains that many mobile apps offer advice on a range of physical exercises for both women and men. These apps are able to measure all sports statistics such as distance, speed and calories consumed. They add that there are also 
specific apps that allow the use of the smartphone as a pedometer to calculate the number of steps a user walks daily by subject. The study shows that these apps are able to positively influence behavior change in the individual using these apps and obtain instant data. Other studies show that m-Health apps send text messages to manage disease and are used for depression treatment and psychological support [5] [6] [7].

[8] shows that mobile health ( $\mathrm{m}$-Health) has emerged as an important area for managing various diseases and evaluating health behavior and interventions. Various mobile techniques have been adopted in many health fields because they offer new methods of measurement and intervention methodologies. This study proved the effectiveness of mobile apps in terms of cost and change of health behavior and treatment through providing a permanent reminder and instant feedback in a timely and adaptive manner. [9] conducted a study about of mobile health apps interface characteristics and usefulness and showed the importance of the ease of navigation and simplicity of customization. They add that aesthetics are important too.

In India, [1] found that obtaining information and guidance is the mostly preferred feature by the majority of users. Healthy young users were interested in using health apps to support their health-related behavior change. Other users expected these apps to be able to record and track goals and behaviors. In Sweden, [10] found that there is a lack of knowledge and awareness about m-Health apps and the respondents do not differ between various kinds of apps but show their willingness to use them if they had more information about them.

In Oman, [11] illustrates that employing technology has a crucial impact for E-health progress in the country because people, organizations and technologies influence its development. Sultan Qaboos University (SQU), the only public university in Oman, was established in 1986. The University sets plans to realize its vision and future role. At present, SQU prepares its undergraduate students to be able to apply the knowledge and skills relevant to the specialization; and communicate effectively and use information and communication technologies [12]. Therefore, the students are well versed in using new technologies such as social media and mobile apps to improve their learning and lives [13].

This study attempts to explore the SQU undergraduate students' perceptions and attitudes towards using m-Health app and its impact on improving their sports and health habits. The following sections explain the study questions, objectives and importance. The methodology section shows the methods, population, sampling techniques, instruments and procedures used. Findings, results, conclusions and recommendations are then discussed in details.

\section{Study Questions}

The study attempts to answer the following questions:

1) What are the perceptions of SQU undergraduate students on the impact of using $\mathrm{m}$-health app on improving their sports and health habits? 
2) Does the m-health app use differ by gender and college variables?

3) What are the attitudes of SQU undergraduate students towards the use of m-Health app?

\section{Study Objectives}

There is a need to investigate how and to what extent m-Health app use exists in the Omani Society, specifically among young users. This study also aims to find out the perceptions of SQU undergraduate students on the impact of m-Health app on improving their sports and health habits and explore their attitudes toward its use.

\section{Study Importance}

The rapid progress in the use of technology innovations in mobile app technologies, m-Health apps in specific, has been a major influence in the daily lives of individuals and society alike. The study is one of the first studies that provide important data about SQU students' views on how the use of m-Health apps changes and improves their sports and health habits.

\section{Methodology}

\subsection{Method}

The descriptive approach was applied combined with focus group interviews. Authors preferred to use more than one instrument because literature shows that it is challenging to investigate their use merely through traditional surveys because individuals' activities and motivations to use them are varied [14].

\subsection{Population and Sample}

The study community includes all the SQU undergraduate students. However, the fieldwork, for both the questionnaires and focus group interviews, is based on a purposive sample consisted of (20) male and female undergraduate students, ages 18 - 24, divided equally, with 5 students from each college, into two humanities colleges (Education and Arts) and two colleges of scientific studies (Science and Agriculture). Although small, the purposive sample is most effective when one needs to study a certain cultural domain and can be used with a number of techniques in data gathering such as a survey [15].

\subsection{Instruments}

1) A questionnaire was adapted from Jain, Udinia and Sahoo, 2017; reviewed and used as a tool for collecting data about the perceptions and attitudes of the students towards the use of the m-Heath app.

2) Focus group interviews were conducted to address the perceptions and attitudes in terms of behavior change, features, and reasons for continued use in an in-depth manner and to triangulate the quantitative findings. 


\subsection{Validity and Reliability}

A panel of experts validated the questionnaire. It was then modified in light of their comments and feedback. Then, the reliability coefficient was calculated and Cronbach's alpha was at (0.688) and considered as a satisfactory reliability level. Focus groups interviews were recorded, transcribed, analyzed; and categorized in themes.

\subsection{Procedure}

The following steps were implemented:

1) The sample individuals were asked to walk or jog everyday using the "Health ${ }^{\otimes}$ " app on their mobile phones for a week.

2) They were asked to record their observations daily by monitoring their health performance, heart rate and calorie data.

3) After the week period of use, the questionnaire was administered to the study sample.

4) The focus group interviews were conducted after additional week of reflection on the practice.

\subsection{Statistical Treatment}

For the quantitative part of the study, theoretical means, standard deviations and t-test were used.

\section{Findings and Discussion}

\subsection{Research Question 1}

To answer the first question, the sample individuals were asked to rate their responses regarding their perceptions on the impact of the use of m-Health app by responding to (12) statements of the questionnaire. Their responses to the instrument items range from (5) which mean they strongly agree the statement to (1) which means they strongly disagree. Table 1 shows the means and standard deviations of undergraduate students' responses to the instrument items.

The results in Table 1 shows positive perceptions of the students on the impact of the use of m-Health apps on their health and sport habits since most responses are higher than the theoretical mean (3.0). The "students' ability to access medical and health information is what makes them use the health software" was ranked as the first statement on their perceptions of the m-Health app use. This finding coincides with [4] [8] and [1] on the importance of using the mobile app in terms of providing instant information and data.

\subsection{Research Question 2}

To answer the second question of the study which states that "Does the $\mathrm{m}$-Health app use differ by gender and college variables?" paired sample $\mathrm{T}$ test was used to test for differences if any. Table 2 shows the results. 
The results in Table 2 show no statistically significant differences between the responses of either males or females, or the science and humanitarian colleges of the sample students. This demonstrates that the gender or college does not influence students' perceptions of their use of m-Health app in general. These findings partially substantiate [2] and [3] on the m-Health apps for science-based colleges.

\subsection{Research Question 3}

To answer the third question, the sample individuals were asked to rate their responses regarding their attitudes toward the use of $m$-Health app by responding to (7) statements of the questionnaire. Their responses to the instrument items range from (5) which mean they strongly agree the statement to (1) which means they strongly disagree. Table 3 shows the means and standard deviations of undergraduate students' responses to the instrument items.

Table 1. Perceptions of undergraduate students on the impact of the use of $m$-Health app $^{*}$.

\begin{tabular}{|c|c|c|}
\hline Statement & Mean & Standard Deviation \\
\hline $\begin{array}{l}\text { My ability to access medical and health } \\
\text { information is what makes me use the health software }\end{array}$ & 4.35 & 7.45 \\
\hline $\begin{array}{l}\text { Graphical and statistical data in the } \\
\text { health software helped me to get a clear and } \\
\text { understandable summary of my daily performance }\end{array}$ & 4.20 & 0.616 \\
\hline $\begin{array}{l}\text { I think that there is a need to design a system } \\
\text { in the health software to reward the user } \\
\text { for his/her health and athletic progress }\end{array}$ & 4.20 & 0.951 \\
\hline $\begin{array}{l}\text { Comparing information and data every day } \\
\text { helps me improve my physical performance }\end{array}$ & 4.10 & 0.718 \\
\hline $\begin{array}{l}\text { I believe that having a mobile phone is } \\
\text { my main drive to use the health app }\end{array}$ & 4.05 & 0.686 \\
\hline $\begin{array}{l}\text { I think that the lack of interest and } \\
\text { knowledge by members of the community } \\
\text { about the health software forms a barrier for its use }\end{array}$ & 4.05 & 0.887 \\
\hline $\begin{array}{l}\text { I see that data provided by the } \\
\text { health software are useful and reliable }\end{array}$ & 3.90 & 0.852 \\
\hline $\begin{array}{l}\text { I see that the daily watching of the health } \\
\text { tracker in the software improves my health and fitness }\end{array}$ & 3.90 & 0.912 \\
\hline $\begin{array}{l}\text { It is better to provide the health software with } \\
\text { lessons on how to use it before you start using it }\end{array}$ & 3.80 & 1.196 \\
\hline $\begin{array}{l}\text { I use multiple health apps to exercise } \\
\text { and monitor my fitness and health }\end{array}$ & 3.45 & 0.686 \\
\hline $\begin{array}{l}\text { I find it difficult to navigate between } \\
\text { health software data and screens }\end{array}$ & 3.05 & 1.050 \\
\hline $\begin{array}{l}\text { Physicians and nurses encourage me } \\
\text { to use the health software }\end{array}$ & 2.70 & 1.081 \\
\hline
\end{tabular}

*Theoretical Mean = 3 (Source: adapted from Jain, J., Udinia, P. and Sahoo, 2017). 
Table 2. T test for paired sample of m-Health app use.

\begin{tabular}{ccccc}
\hline \multirow{2}{*}{ Variable } & \multicolumn{2}{c}{ Test for Equality of Variances } & \multicolumn{2}{r}{ T-test for Equality of Means } \\
\cline { 2 - 5 } & $\mathrm{T}$ & $\mathrm{Df}$ & $\mathrm{F}$ & Sig. \\
\hline Gender & 1.526 & 18 & 0.011 & 0.916 \\
College & 2.359 & 18 & 3.425 & 0.081 \\
\hline
\end{tabular}

Table 3. Means and standard deviations of students' responses regarding their attitudes toward the use of m-Health app.

\begin{tabular}{|c|c|c|}
\hline Statement & Mean & $\begin{array}{l}\text { Standard } \\
\text { Deviation }\end{array}$ \\
\hline $\begin{array}{l}\text { I think exercise, jogging and calorie/weight } \\
\text { control are the common reason for using m-Health app }\end{array}$ & 4.25 & 1.020 \\
\hline $\begin{array}{l}\text { I think that m-Health app contributes to the improvement } \\
\text { of general health care among members of the community }\end{array}$ & 4.10 & 0.553 \\
\hline $\begin{array}{l}\text { I think using the health software is useful to check my fitness } \\
\text { and health and to reduce the cost of visiting clinics and doctors }\end{array}$ & 3.85 & 1.040 \\
\hline Health software has become a part of my daily life & 3.70 & 0.979 \\
\hline I feel stress when using the health software and understanding its data & 3.35 & 0.587 \\
\hline I feel that health does not help me to follow up on my health and sports & 3.05 & 0.759 \\
\hline $\begin{array}{l}\text { I think the design of the health software is inconvenient } \\
\text { to enable the user to monitor his/her data on a daily basis }\end{array}$ & 2.95 & 0.686 \\
\hline
\end{tabular}

Responses in Table 3 were positive on all statement that measure the students' attitudes toward the use of the mobile health app in terms of content, design and use, as most responses are higher than the theoretical mean (3.0). These findings are consistent with the results of [4] study on positive attitudes toward $\mathrm{m}$-Health apps and their impact on users' behavior after using them.

\subsection{Qualitative Analysis}

Inductive thematic analysis of the above qualitative data was conducted. Four main themes were recognized in terms of students' perceptions towards using $\mathrm{m}$-Health app as it 1) increases health performance, 2) plays a stimulating role, 3) provides support for physical fitness, 4) stands good chance for future use. The followings explain these themes:

- Theme 1: m-health app increases health performance: Most students generally substantiated the quantitative findings by stating that the use of such software keeps them informed about their health and physical level along with their heartbeat rate and calories loss. They also said that the app encourages them to walk longer distances and reduce dependence on the vehicle at simple distances. One student reiterated the same idea saying that: "It increases my physical performance... because it makes me aware of how far distances I have walked/ran". These findings generally corroborates the results of [1] study. 
- Theme 2: $\mathrm{m}$-health app plays a stimulating role: One student said, "It motivates me more to exercise continuously and orderly". Some students stated it reflects positively on their psychological and physical state and make them pay more attention to their daily routines and unhealthy habits. Another student interestingly commented that: "It stimulates the individual to do more by comparing his activity day after day and gives a good impression of the individual health as well as it encourages us to continue our sports effort for more goal achievement competing with our previous results".

- Theme 3: m-health app provides support for physical fitness: A student expressed his satisfaction with the health software "the app is excellent and the sign of my satisfaction with it is that I highly depend on this app". Another female student said, "This is the first time I have used a healthy app but I am very encouraged to use these apps and take advantage of them".

- Theme 4: m-health app stands good chance for future use: Some students recommended the software for community members and patients as it makes them more committed to sports activities. Another student said that she "told all her family members that these apps are useful and advised them to use them". On the contrary, her colleague emphasized, "I have used this app for years and I have been following it continuously". Some said they connect them to wearable devices while walking. The majority of the sample students do not see any obstacles to continue using the m-Health app. These findings agree to some extent with [10] and [16].

\section{Conclusion}

The primary objective of this study was to explore the Sultan Qaboos University undergraduate students' perceptions and attitudes towards using m-Health app and its impact on improving their sports and health habits. In general, respondents were positive in their responses to all statements that measure their attitudes towards mobile health app. However, the study was limited to the campus students besides some research and technical limitation concerning the small size of the sample and the various software versions used. Therefore, drawn conclusions should be carefully considered when intended for wider scale application.

\section{Recommendations}

According to the above findings, the study recommends the followings:

1) Raise the awareness of the university and the local community members toward the importance of using mobile health apps to improve their health.

2) Encourage individuals to use these apps by the medical and health authorities.

3) Design advanced m-Health apps with programmed personal health and medical data of their users.

4) Conduct the same research but on the public audience and local community. 


\section{Acknowledgements}

The research team would like to thank the students of the study sample for their participation in the fieldwork.

\section{Conflicts of Interest}

The authors declare no conflicts of interest regarding the publication of this paper.

\section{References}

[1] Jain, J., Udinia, P. and Sahoo, PK. (2017) Qualitative Study to Analyze the Pros-Cons and Consumer's Perception towards mHealth Apps. The Pharma Innovation Journal, 6, 43-48.

[2] George, T., DeCristofaro, C. and Murphy, P. and Sims, A. (2017) Student Perceptions and Acceptance of Mobile Technology in an Undergraduate Nursing Program. Healthcare, 5, 1-8. http://www.mdpi.com/journal/healthcare

[3] Subhash, T. and Bapurao, T. (2015) Perception of Medical Students for Utility of Mobile Technology Use in Medical Education. International Journal of Medicine and Public Health, 5, 305-311. https://doi.org/10.4103/2230-8598.165959

[4] Ber, F., Giacometti, M., Gualano, M., et al. (2014) Smartphones and Health Promotion: A Review of the Evidence. Journal of Medical Systems, 38, Article ID: 9995. https://doi.org/10.1007/s10916-013-9995-7

[5] Bexelius, C., Lof, M., Sandin, S., Lagerros, Y.T., Forsum, E. and Litton, J.E. (2010) Measures of Physical Activity Using Cell Phones: Validation Using Criterion Methods. Journal of Medical Internet Research, 12, e2. https://doi.org/10.2196/jmir.1298

[6] Free, C., Phillips, G., Galli, L., Watson, L., Felix, L., Edwards, P., Patel, V. and Haines, A. (2013) The Effectiveness of Mobile-Health Technology-Based Health Behaviour Change or Disease Management Interventions for Health Care Consumers: A Systematic Review. PLoS Medicine, 10, e1001362. https://doi.org/10.1371/journal.pmed.1001362

[7] Grassi, A., Gaggioli, A. and Riva, G. (2009) The Green Valley: The Use of Mobile Narratives for Reducing Stress in Commuters. CyberPsychology \& Behavior, 12, 155-161. https://doi.org/10.1089/cpb.2008.0156

[8] O'Reilly, G.A. and Spruijt-Metz, D. (2013) Current mHealth Technologies for Physical Activity Assessment and Promotion. American Journal of Preventive Medicine, 45, 501-507. https://doi.org/10.1016/j.amepre.2013.05.012

[9] Ericsson, A., Pettersson, J. and Sjögren, F. (2018) Perceived Usefulness of User Interface Characteristics for Mobile Health Applications. Örebro Universitet, Handelshögskolan-Informatik.

[10] Altmann, V. and Gries, M. (2017) Factors Influencing the Usage Intention of mHealth Apps: An Empirical Study on the Example of Sweden. MA Thesis, Business Administration, Karlstad Business School, Sweden.

[11] Al-Maskari, G. (2004) Exploiting Internet Technologies in Health Care of Sultanate of Oman, BSc Information Systems with Management Studies 2004/2005.

https://minerva.leeds.ac.uk/bbcswebdav/orgs/SCH_Computing/FYProj/reports/040 5/Al-Maskari.pdf

[12] SQU (2018) Graduate Attributes. Sultan Qaboos University. 
https://www.squ.edu.om/About/About-SQU/SQU-Graduate-Attributes

[13] Al Musawi, A. and Ammar, M. (2015) Students Use of the Internet and Social Networking Sites for Learning and Other Activities at Sultan Qaboos University. International Journal of Social Media and Interactive Learning Environments, 3, 142-161. https://doi.org/10.1504/IJSMILE.2015.070775

[14] Bol, N., Helberger, N. and Weert. J. (2018) Differences in Mobile Health App Use: A Source of New Digital Inequalities? The Information Society, 34, 183-193. https://doi.org/10.1080/01972243.2018.1438550

[15] Tongco, D. (2007) Purposive Sampling as a Tool for Informant Selection. Ethnobotany Research \& Applications, 5, 147-158.

https://scholarspace.manoa.hawaii.edu/bitstream/10125/227/4/I1547-3465-05-147.pdf https://doi.org/10.17348/era.5.0.147-158

[16] Hongu, N., Going, S.B., Orr, B.J., et al. (2014) Mobile Technologies for Promoting Health and Physical Activity. ACSMs Health Fit Journal, 18, 8-15.

https://doi.org/10.1249/FIT.0000000000000050 